\title{
The role and value of nurses in care provision: Views and expectations of Emirati Nationals in the western region of Abu Dhabi, United Arab Emirates
}

\author{
Sharon M. Brownie*1,2, Rachel C. Rossiter ${ }^{3}$, Abeer Omar Hamad ${ }^{4}$, Salah Aqtash ${ }^{5,6}$ \\ ${ }^{1}$ Oxford PRAXIS Forum, Green Templeton College, Oxford University, United Kingdom \\ ${ }^{2}$ School of Medicine, Griffith Health, Griffith University, Australia \\ ${ }^{3}$ School of Nursing, Midwifery \& Indigenous Health, Charles Sturt University, Australia \\ ${ }^{4}$ Al-Gharbia Hospitals, Abu Dhabi, United Arab Emirates \\ ${ }^{5}$ College of Health Sciences, School of Nursing, Walden University, Minneapolis, MN, United States \\ ${ }^{6}$ School of Nursing and Midwifery, Griffith University, Australia
}

Received: October 19, 2017

DOI: $10.5430 /$ jha.v6n6p42
Accepted: November 12, 2017

Online Published: November 20, 2017

\begin{abstract}
Background: Reliable health user information is needed to effectively organize nursing services and deliver quality patientcentered care. Nurse leaders of Al Gharbia Health Services (AGHS) noted that although budget data and general workforce information were readily available, detailed information about patient experiences, views, and expectations was lacking.

Objective: This study aimed to obtain preliminary data regarding health and nursing service expectations of Emirati nationals in the remote western region of Abu Dhabi, United Arab Emirates (UAE).

Methods: This study used qualitative descriptive methodology. Semi-structured interviews were conducted with a sample of Emirati families who had recently accessed AGHS. Interviews focused on service user understanding and expectations of the role of nurses, nursing services, and the health service overall.

Results: Emirati nationals' views and expectations regarding nurses' role and function in the healthcare team were highlighted. Participants' expectations and the attributes they valued were distributed across two distinct areas: clinical competence and the "softer" skills of compassion, caring, and respect.

Conclusions: These findings facilitate understanding of the expectations of Emirati health service users. Importantly, the results counter regional perceptions of nursing under-valued as a servant role across the UAE and broader Gulf Cooperation Council region. The findings may inform a range of activities including: a large-scale survey regarding the views and expectations of Emirati health service users; pre-service nursing education and nursing in-service development; and the recruitment of Emirati nationals to the nursing profession. Further investigation regarding perceptions and valuing of nursing within the Emirati community is warranted.
\end{abstract}

Key Words: Patient-centered care, Patient expectations, Health services, Nursing role, Nursing services, Rural health

*Correspondence: Sharon M. Brownie; Email: Sharon.brownie@aku.edu; Address: Oxford PRAXIS Forum, Green Templeton College, Oxford University, UK; Griffith Health, Griffith University, Australia. 


\section{INTRODUCTION}

The importance of eliciting the voices of patients and families who access healthcare services is increasingly recognized as essential information in health service planning and to effectively organize nursing services and deliver quality patientcentered care. Effective health and nursing service delivery is bounded by budget constraints and health workforce availability; the impacts of such constraints are explicable. Nurse leaders of Al Gharbia Health Services (AGHS) in the United Arab Emirates (UAE) found that information outlining the necessary infrastructure, equipment, and budget data, along with general workforce information was readily available to inform organization of nursing services. However, little information was available on patient experiences, views, and expectations, especially regarding changes in expectations about health service delivery in contexts such as Al Gharbia that are influenced by rapid modernization. Multiple factors affect the ability of a healthcare service to deliver quality care, including characteristics of the professional workforce, individual abilities, competence, and experience. ${ }^{[1]}$ Given the boundaries that impact on service delivery, effective health service coverage can only be achieved if services are designed to be integrated and people-centered. This paper reports an exploratory study to obtain preliminary data regarding expectations for health and nursing services among Emirati nationals in a remote western region of Abu Dhabi, UAE.

This study was undertaken in the $\mathrm{Al}$ Gharbia region in the Emirate of Abu Dhabi, UAE (see Figure 1). Also known as the "western region", $\mathrm{Al}$ Gharbia covers an area of $35,250 \mathrm{~km}^{2}$, and accounts for $60 \%$ of the total land mass of Abu Dhabi inclusive of the nation's largest oil and gas reserves. ${ }^{[2]}$ The region has an estimated population of 310,000 people, which is $11.8 \%$ of the total population of the Emirate. This is the most sparsely populated region of Abu Dhabi, with 8.9 people per $\mathrm{km}^{2}$. ${ }^{[3]} \mathrm{Al}$ Gharbia presents specific opportunities and challenges for healthcare delivery, as it is a rurally remote and culturally unique context, influenced by rapid modernization over the past 40 years. At around 29,550 people, Emirati nationals constitute just under $10 \%$ of the overall population of the region. The remaining $90.6 \%$ are predominantly male oil and gas industry employees. Other non-Emirati include local development personnel and service workers such as teachers, nurses, and other health professionals. $^{[3]}$

Al Gharbia has well-established health services. All members of the nursing workforce have at least 2 years of experience. ${ }^{[4]}$ At the time of this study, the AGHS had six hospitals with a 358-bed capacity, one family medicine center, and three primary care clinics. The hospital nursing manpower included 585 budgeted nursing positions; 435 positions were filled, with the remainder in the process of being filled. Only one of these positions was filled by an Emirati nursing graduate. ${ }^{[4]}$ The AGHS provides primary, secondary, and selective tertiary care to patients in the region. People requiring interventions for high-risk conditions are usually transferred to other hospitals in the city of Abu Dhabi.

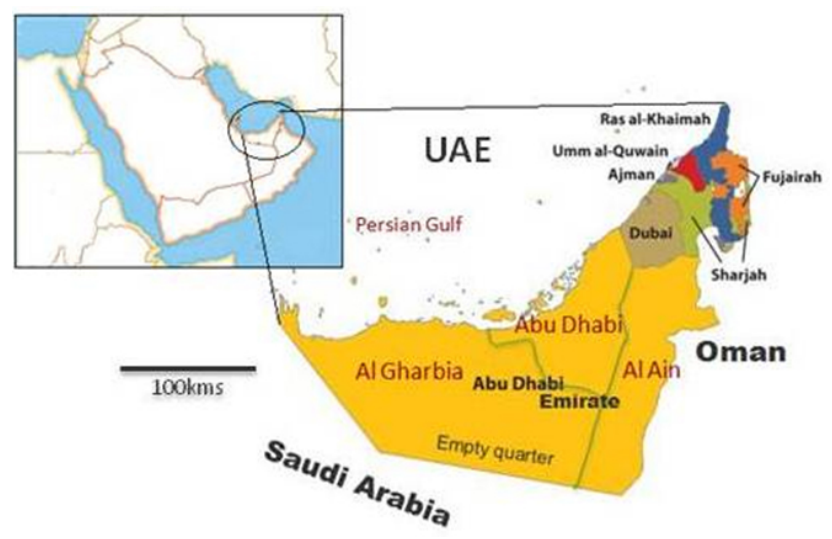

Figure 1. Al-Gharbia region, Abu Dhabi, UAE

\section{MeTHODS}

This study aimed to fill an identified gap in the literature by exploring and describing self-identified health and nursing service needs and expectations of Emirati nationals in relation to health services in general and associated nursing services, including the role of nurses in care provision. This paper focuses on Emirati nationals' understanding of the role of nurses and their expectations of nursing care.

The absence of previous research in this area informed the study methodology. Without preliminary data, developing a survey or similar quantitative tool was contraindicated. Therefore, a clear description of the phenomenon under consideration was sought. Based on this description, a qualitative descriptive method was adopted, with data collected in semistructured focus group interviews. The researchers aimed to elicit Emirati service users' understanding and expectations of the role of nurses, nursing services, and the health service overall. Questions to guide the focus group interviews were developed by the research team in consultation with nursing mangers of participating facilities. These questions were piloted with a group of healthcare clinicians during a workshop to introduce attendees to qualitative research methods. Minor adjustments were made to the questions following discussion and feedback from workshop participants.

As potential study participants (i.e., Emirati families who had recently accessed AGHS in this remote region) might be non-English speaking, meaningful communication between 
participants and non-Arabic speaking researchers was a potential barrier. Participant information and consent forms were translated from English to Arabic, and back-translated to check the accuracy of the translation. Fluent bi-lingual co-investigators were part of the research team, including a bi-lingual Emirati national who was involved in early study design and ethics approval.

\subsection{Ethics approval}

Application for ethics clearance was submitted to the AGHS Institutional Research and Ethics Committee before the study started. Clearance was granted on March 17, 2014 (AGHIREC-014-001). Consent forms were signed by all participants.

\subsection{Participants}

Participants were Emirati families (family unit comprising Emirati nationals) who had recently accessed AGHS. Inclusion criteria were participants who: were Emirati nationals living in the AGHS catchment area, were returning users of the service, had accessed either an outpatient or inpatient AGHS service in the preceding 3 months, and volunteered to participate. Non-Emirati nationals, people resident outside the AGHS catchment area, first time services users, people with an intellectual disability or who were mentally infirm, and children and young people aged under 18 years were excluded from the study.

\subsection{Participant recruitment}

Administrative and/or nursing staff in outpatient clinics or admitting inpatient services distributed an Arabic and English information sheet to eligible patients. Those who expressed interest in participating were provided with a consent form. Once verbal consent had been obtained, contact details were provided to the members of the interviews team to schedule an interview. Consent forms were signed before the interviews occurred. Recruitment of participants ceased when candidates had been recruited for three focus groups as the perspectives expressed in the third focus group demonstrated a strong similarity to those expressed by the participants in the first and second focus groups.

\subsection{Focus groups}

Three focus groups were conducted with an overall total of 10 participants ( 9 female and 1 male) (see Table 1) as a small scale qualitative descriptive study designed as an initial exploration to inform later larger studies.

\subsection{Data collection}

Focus group interviews occurred at the time and location chosen by participants. All participants chose to meet with the interviewers at the healthcare facility. Two bi-lingual co-investigators conducted each interview. Interviews were recorded electronically, with participants' permission.

Table 1. Participant demographics and interview locations

\begin{tabular}{|c|c|c|c|c|c|}
\hline \multirow{2}{*}{$\begin{array}{l}\text { Focus } \\
\text { Group }\end{array}$} & \multirow{2}{*}{ Location } & \multicolumn{4}{|c|}{ Participants } \\
\hline & & Gender & Age & Health Status & Service usage \\
\hline \multirow{4}{*}{1} & Remote facility $-120 \mathrm{kms}$ to next hospital & F & 35 & Well & Frequent \\
\hline & - Med/surg services & $\mathrm{F}$ & 42 & Well & Infrequent \\
\hline & - Laboratory \& X-ray & $\mathrm{F}$ & 41 & Well & Frequent \\
\hline & - Midwifery & & & & \\
\hline \multirow{3}{*}{2} & $\begin{array}{l}\text { Hospital }-1 \mathrm{~km} \text { to next facility } \\
\text { - Med/surg services }\end{array}$ & $\mathrm{M}^{*}$ & 40 & $\begin{array}{l}\text { - Type } 2 \text { DM } \\
\text { - Hyperlipidemia }\end{array}$ & Frequent \\
\hline & - Laboratory \& X-ray & $\mathrm{F}$ & 50 & Hypertension & Frequent \\
\hline & $\begin{array}{l}\text { - Midwifery } \\
\text { - Physiotherapy }\end{array}$ & $\mathrm{F}$ & 51 & Type 2 DM & Frequent \\
\hline \multirow{5}{*}{3} & \multirow{5}{*}{$\begin{array}{l}\text { Family medicine centre - } 5 \mathrm{kms} \text { from Location } 2 \\
\text { - Antenatal care } \\
\text { - Primary health care } \\
\text { - Laboratory \& X-ray }\end{array}$} & $\mathrm{F}$ & 40 & Type 2 DM & Frequent \\
\hline & & $\mathrm{F}$ & 62 & - Type 2 DM & Frequent \\
\hline & & & & - Hypertension & \\
\hline & & $\mathrm{F}$ & 25 & Well & Frequent \\
\hline & & $\mathrm{F}$ & 28 & Well & Frequent \\
\hline
\end{tabular}

Note. ${ }^{*}$ The findings presented do not include the perspective of the one male participant. For completeness, he does remain identified as a participant in the second focus group

\subsection{Data analysis}

First, each interview recording was transcribed in Arabic and then translated into English. The translations were crosschecked by the bi-lingual co-investigators, both of whom met the criteria for sociolinguistic competence as outlined by Squires. ${ }^{[5]}$ The conceptual framework used for this stage of the study was Yin's five phases of analysis. ${ }^{[6]}$ Phase 1 involved compiling the database, comprising English and 
Arabic transcriptions of each focus group interview, handwritten notes made by the interviewers, email correspondence, and additional handwritten notes reflecting on the data collection process. Phase 2 involved disassembling the data. Responses to questions regarding the role of nurses and participants' expectations of nursing and the healthcare service were extracted from the database. These first two phases used the English translations of the interview transcripts, and were repeated by the bi-lingual co-investigators to verify and check authenticity against the Arabic transcripts. Phase 3 was reassembling the data into potential themes. This was first undertaken using the English transcripts and repeated by the bi-lingual co-investigators against the Arabic versions to ensure the authenticity of participants' voices was maintained as the analysis proceeded. ${ }^{[7]}$ The bi-lingual interviewers were deeply immersed in the healthcare environment and able to contextualize and explain finer nuances of the transcripts that might not have been accessible to the non-Arabic speaking researchers. The transcripts were then re-read to check the context in which the extracted responses were embedded. This was followed by identification, reassembling, and grouping of the extracts that validated each other with descriptors and examples into potential themes. Phase 4 involved interpreting the data, and was undertaken with all research team members. Emergent themes and subthemes were cross-checked with all research team members. The non-Arabic speaking researchers paid particular attention during this phase to ensure that their understanding and interpretation of specific Islamic spiritual perspectives and cultural understandings accurately reflected the participants' perspectives. The final stage of the data analysis (Phase 5) analysis drew together the reassembled data and interpretation of the data to identify two central themes are reported: (1) nursing as an art and a science, and (2) what we want from nurses. Although these phases are described sequentially, the process of analysis was non-linear, with movement back and forward across phases and frequent return to the database.

\section{RESUlts}

Interpretation of the data revealed shared perspectives across the three focus groups regarding the role of nurses in delivering healthcare and in their expectations of what was helpful or unhelpful in the way care was delivered. Nine out of ten participants were female, thus the findings primarily reflect a female perspective on the role and expectations of nurses. The one male voice has, however, been included as a participant in Focus Group 2 and while his perspective is perhaps expressed a little more stridently, it was nevertheless identified as congruent with that of the female voices. Partic- ipants' understanding of nursing as both an art and a science emerged as a key theme (see Figure 2), and categories illustrating the art or science of nursing were identified. This theme is presented below with quotations illustrating these concepts in further detail. Pseudonyms have been used to ensure participant confidentiality.

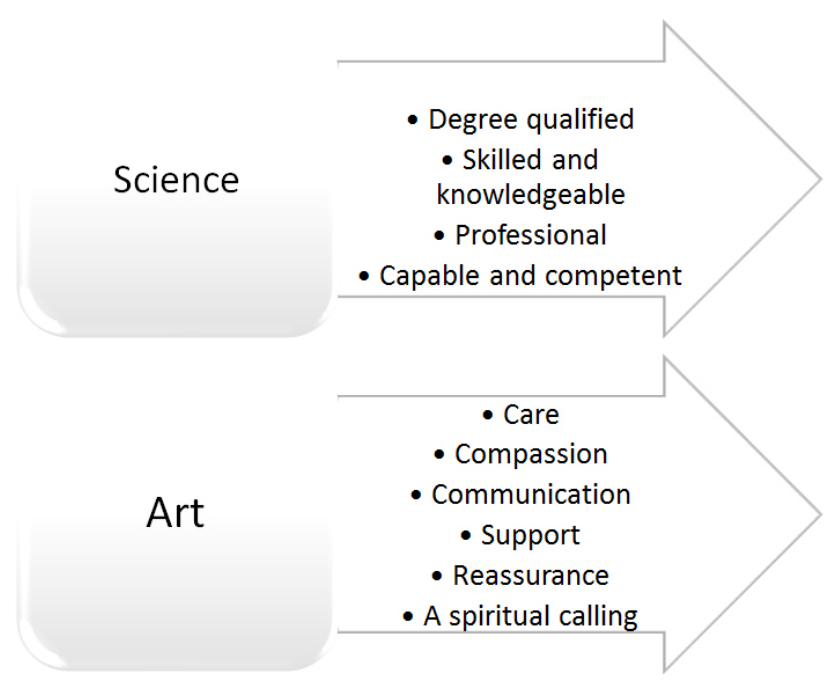

Figure 2. Nursing: An art and a science

\subsection{Nursing as an art and a science}

When asked how they viewed the role of the nurse, participants unequivocally refuted suggestions that the nursing role is comparable with that of a housemaid. Instead, participants offered their perspectives on the role of a nurse.

"... Nursing in itself, is a science and it is unfair to have this description (housemaid) for comparison." (Fatima)

The notion of nursing as a science was further explained with reference to the qualifications required to become a nurse (diploma of nursing, college/bachelor's degree). Nursing was also described as having a supporting function in facilitating the work of medical officers. A range of tasks were listed as within the scope of nursing practice.

"It is not similar to the housemaid's role, the nurse deals directly with the patient. The nurse is an educated person and a holder of a high academic certificate. The nurse must be qualified and capable of examining the patient's blood pressure, temperature, weight, height, and getting him ready prior to check up by the doctor. The nurse assists the doctor properly in performing his/her work and in providing the patient with the required treatment. In general, the nurses are helpful to both doctor and patient." (Maryam)

This view of nurses as skilled in a range of different tasks was repeated by several participants. Many participants described similar tasks, suggesting that the perception of nurses 
as having a wide skill-base was commonly held. The most technical of nursing skills was described as:

"She/he gives intramuscular injection or intravenous injection." (Reem)

The idea of a nurse as an independent and autonomous healthcare practitioner was not evident in any comments from par- “. ticipants. Nevertheless, it is noteworthy that although the nursing role was seen as supportive rather than independent of the medical officers' role, participants emphasized this function as integral to medical officers' capacity to deliver effective care.

"The nursing profession is as good as the doctor's profession... I think the doctor's success is closely related to the success of the nursing profession." (Fatima)

"I think the nurse is similar to the doctor... the midwife helps more than the doctor. . the nurse monitors the patient's health, works hard, is dedicated and loyal." (Shamma)

In addition to these technical tasks, participants described nurses has having a role in the provision of patient education. One participant emphasized the value she ascribed to a nurse who took the time to provide specific healthcare advice.

"In. . clinic, a nurse asked me to drink a lot of water when a special injection was given to me. She told me that a lack of water in the body will badly affect the function of the kidney. I really appreciated her advice and she deserves an appreciation letter for such advice." (Fatima)

However, the recognition of this educational role as perhaps extending beyond what was generally expected from a nurse was apparent in that participant's suggestion that the nurse concerned deserved an appreciation letter for providing helpful advice.

In marked contrast to the somewhat circumscribed descriptions of the skills undertaken by a nurse as a nurse scientist, the "soft" skills of nursing as an art were elaborated in more detail. Participants spoke fondly of their contact with nurses. Their comments indicated they placed high value on the care, compassion, reassurance, and support offered by nurses. The worth attributed to the presence, gentleness, and encouraging words was emphasized repeatedly by many participants.

"The nurse helps the patient a lot and gives him the motive he needs. In the presence of the nurse, I don't feel that I'm scared." (Shamma)

"Sometimes, it is good if the nurses say simple words like "good" or even if they gently pat on the patient's shoulder." (Reem)

"Patient feels that he/she is safe, feels with tenderness when served by those nurses." (Maryam)

Arabic has been described as verbally expressive and visual language. Comments made by Arabic speaking participants highlighted that the impact of a face lit by a smile was noteworthy and significant.

"... nursing staff is also good with their lovely wide smiles. They treat the patients friendly, and always ready to support and help the patients." (Reem)

“The nurses. . . with their lovely smiles.” (Maha)

Participants" descriptions of these "soft skills" may perhaps be seen individually as "little things", or as trivial aspects of nursing care. However, taken together, they provide a clear picture of elements participants' valued about the care provided by nurses. One participant went further to describe a particular nurse and midwife as "one of the most dedicated nurses".

"The patient considers her as her dear sister as she willingly, provides the required support and assistance to patients and to me as well... I feel that I'm safe and secure in the presence of this nurse and I do not call my mother or anybody else to be with me at moment of delivery." (Maryam)

Comments relating to feeling safe and secure when cared for by a nurse recurred throughout the interview transcripts. This highlighted the unquestionable impact that this perception had on participants' understanding of the role that a nurse plays in reducing fear when they were unwell and in a (possibly unfamiliar) healthcare environment.

Many of the comments made by participants indicated that in their perception, nursing was not limited to skilled technical tasks or simply providing care; the art of nursing was regarded as a spiritual calling. Participants presented a perspective of the role of a nurse as extending beyond that of a skilled professional delivering care and compassion, to encompass a role offered as a humanitarian service.

"We feel that nurses are doing their work with full faith and dedication..." (Khaled)

“... it makes you able to provide humanitarian services to those who are in need of their support, communicate and interact with people under all circumstances.” (Maryam)

“... bear in mind that people who are practicing such a profession will be rewarded by patients and by others through their Duaa' saying (May Allah (SW) reward you)." (Khaled)

Participants' identification of nursing as a humanitarian service aligned with the tenets of Islam were clearly identified with the male participant more explicitly referring to the link between nursing and spiritual beliefs. This perspective 
appeared to have wider implications that were evident in comments that indicated some participants regarded nursing as a profession that they would not mind their child/children studying. However, female participants noted that cultural constraints presented difficulties for an Emirati female who wished to practice as a nurse.

"The working hours represent a major problem for UAE females whether they are single or married. Working at a daytime shift in the morning till afternoon is OK for these females, but working at a night shift is difficult and impossible. Females in particular, are not allowed to leave the house alone in the evening time. On the other side, males are excluded from this prevention and they can go at any time of the day and do whatever they want without questioning." (Shamma)

Further questioning regarding this viewpoint revealed this cultural perspective was more strongly held in the remote areas of the Al Gharbia region. Therefore, participants' perception of nursing as more than a secular role, indeed as a spiritual calling, appeared to conflict with strongly held cultural viewpoints and behaviors. Although participants described how they viewed the role of a nurse and what they valued about the way in which they had been cared for, they also clearly identified what constituted desirable professional practice. These expectations are presented under the second theme that emerged from the data.

\subsection{What participants wanted from nurses}

The value attributed to a nurse's communication style, skill, and ability to speak in the participants' native language (i.e., Arabic) appeared frequently throughout the transcripts. Contrary to anecdotal reports that Emirati patients expect priority treatment, one participant stated:

"Waiting for an hour or so will not be a problem for me if I'm received nicely and gently by the nurse. Using the proper technique in talking to/dealing with the patients is very much important in this regard." (Fatima)

Again, rather than voice expectations of preferential treatment, perceived unequal or unfair treatment was spoken of with concern by the one male participant.

"Nurses (noted as non-Emirati expatriate) in the past were not professional in dealing with patients, they were tough and severe to an extent that made you sometime, fight with them. Many of them were biased and treated people based on their nationalities. In the past, I used to see some of the nurses dealing with the patients in improper manner. For example, they deal with some people in a tough manner (abridged). Nowadays, we see the treatment is much better and the new generation of nurses dealing with people and patients equally

Published by Sciedu Press without discrimination or favoritism.” (Khaled)

In contrast, comments from some participants indicated that the skill exhibited by nurses able to effectively care for specific populations (e.g., infants and children) was valued and commended.

"I know some nurses who are specialized and assigned to work in particular wards such as the infant's ward. Those nurses adjust their communication style in dealing with them in order to match the child's level of thinking. No features of fear or horror can be seen or felt (by the child)." (Fatima)

Participants' also perceived that the ability to assist a person who is anxious and in pain was central to a nurse's role.

"The old patients specifically, want to know or hear anything from the nurse or the doctor about their health. They need to hear good things, but when the nurse remains silent or does not say anything, this will affect the patient's health adversely and make him very much anxious." (Reem)

Other participants described this ability to properly assist a person in distress as an area in which nurses required future training and development. The male participant specifically identified the importance of additional guidance and direction for nurses working with people who could perhaps be identified as difficult.

"The patient sometimes looks nervous or upset due to the pain he or she suffers from. I request that these nurses be directed or guided on how to deal professionally with these patients specially, the patients who are rough to deal with." (Khaled)

Challenges arising from communication and cultural difficulties were readily apparent in many comments. The lack of a shared language emerged as a key issue for these participants. While many participants reported that their experience of nurses from other nationalities (e.g., Filipino or Indian) was good, an inability to speak Arabic impacted on their perceptions of care.

"The language is one of the major problems." (Noura)

"Sure the Arabic nurses are better. We can communicate better with them." (Fatima)

“... some of the patients do not speak or understand the English language. They face some difficulties in communicating with the nurses. The language is considered as one of the major problems.” (Reem)

A further impact of cultural differences and communication difficulties emerged in relation to issues concerning confidentiality and privacy. Participants' noted an additional effect of being cared for by a non-Arabic speaking nurse in terms of significant implications for patient safety, particularly if a 
person did not understand what was being asked of them.

“... some of the nurses speak loudly and do not take into consideration the privacy of the patient. It is good if they speak slowly with the patient and when asking him any question." (Reem)

Overall, these participants appeared to expect behavior consistent with the core values of the nursing profession: to be treated with respect, care, and compassion and to be supported during difficult times by a nurse able to communicate in their own language.

\section{Discussion}

The findings reported in this study are of particular interest given the lack of relevant research available to inform service development. A major finding was that although nursing was described as a scientific endeavor requiring tertiary-level education, descriptions of nursing activities were limited, with little reference to higher order clinical or technical skills. This might be attributable to participants having little exposure to nursing activities in clinical settings other than outpatient services. Conversely, it may reflect a somewhat limited role for nurses in the clinical contexts with which participants were familiar. However, viewing nursing purely as a series of technical skills and functions fails to capture the fundamental nature of nursing. Jasmine ${ }^{[8]}$ suggested that "the essence of professional nursing is best embraced by an approach that includes its artistic and scientific dimensions". Similarly, Alligood ${ }^{[9]}$ quoting Abdellah, Beland, Martin, and Matheney's ${ }^{[10]}$ work emphasized two aspects of the profession, asserting that nursing, "is based on an art and science that moulds (shapes) the attitudes, intellectual competencies, and technical skills of the individual nurse into the desire and ability to help people, sick or well, cope with their health needs."

In 1979, Watson, a nursing theorist, described caring as a core component of nursing as a profession in Nursing: The Philosophy and Science of Caring. ${ }^{[11]}$ Almost 30 years later, Watson reiterated that "Caring Science is the essence of nursing and the foundational disciplinary core of the profession". ${ }^{[2]}$ Participants in this study emphasized the importance of caring and related qualities such as compassion, and the provision of support and reassurance. This emphasis is consistent with Watson's perspective of nursing as a science of caring, and with the essential qualities of professional nursing as described by contemporary undergraduate nursing students. The most common quality identified was caring, followed by knowledge/understanding, empathy, work, communication, and skills. ${ }^{[13]}$ The nursing qualities valued by participants in this study are also consistent with a number of qualities recently identified in a mixed multiphase research project to develop a Person-centered Practice Inventory-Staff (PCIPI-S) that measures staff perceptions of person-centered practice. ${ }^{[14]}$ In two consecutive Delphi studies undertaken for that project, an international sample of nursing professionals identified qualities such as professional competence, well-developed interpersonal skills, having a sympathetic presence, providing holistic care, and clarity of beliefs and values as integral to person-centered practice. ${ }^{[14]}$ The geographic and cultural context of participants in the present study could be seen as far removed from that of American nursing theorists (e.g., Watson and Abdullah and colleagues), and the nursing students and staff discussed in previous studies. Nevertheless, there appears to be shared valuing of key components of what this study describes as the art of nursing and what Watson conceptualized as the science of caring.

Participants in this study felt that the art of nursing incorporated both humanitarian and spiritual components. Lovering ${ }^{[15]}$ described spirituality and caring expressed by Arab Muslim nurses as an interconnection between a shared spirituality with patients and families. She refers to a verse in the Qur' aan [An-Nahl 5:23]: "if anyone has saved a life, it would be as if he has saved the life of the whole of mankind," suggesting that this is significant to the belief that nursing is a spiritual action that will bring rewards in the afterlife. ${ }^{[16]}$ The view of nursing as a spiritual calling offering benefits to the recipient of the nurse's care and to the nurse as a recipient of thanks from patients and supplications (duaa) to Allah expressed by participants in this study echoes this perspective. Research seeking perspectives of Jordanian nurses reported that participants identified spirituality and spiritual care as a priority and a core competency of nursing. ${ }^{[17]}$ An expanded understanding of nursing as viewed in Islamic sources describes the nursing role as one that is focused on assisting the patient to reach his/her full human potential, a role in which "the person is viewed from a holistic lens and spiritual development is more important than physical care". ${ }^{[18]}$ However, identifying nursing as a spiritual calling is not limited to Islamic perspectives of nursing. A Scandinavian integrative review ${ }^{[19]}$ examining spirituality and spiritual values in nursing reported that the separate concepts of spirituality and caring were essentially the same. Those authors concluded that "it was obvious that spirituality and spiritual values in the context of nursing are closely intertwined with the concept of caring...". [19]

Contrary to anecdotal and published data, these findings portrayed a positive perspective of the nursing role that extended to it being a profession potentially suitable for participants' daughters, although not without significant cultural challenges. However, although nursing was seen as a hu- 
manitarian act, challenges for Emirati women in terms of work involving shift work and contact with males outside the family were clearly identified. Over a decade ago, the UAE nursing workforce was predominantly transient expatriate nurses, with only $3 \%$ of the workforce identified as Emirati nationals. ${ }^{[20]}$ El-Haddad ${ }^{[20]}$ suggested that one of the factors contributing to the low-uptake of nursing as a career was the low status accorded to the profession in the UAE. The perceived low status of nursing as a profession is not unique to the UAE, but is consistent with widespread variations in the esteem in which nursing as a profession is held across the globe. Therefore, while the present participants did not appear to view nursing as a low-status profession, the cultural constraints that were mentioned suggest some significant difficulties for full participation in nursing roles that require availability for shift work and care of both males and females.

A common thread in the interviews was the impact on participants of communication difficulties resulting from the lack of a shared language. Participants identified this as the "major problem". A recent study by Alahmmari ${ }^{[21]}$ explored barriers to effective communication in the Saudi Arabian healthcare context; similar to the UAE, the Saudi Arabian nursing workforce is mostly expatriate and $72 \%$ of non-Saudi nursing participants identified their unfamiliarity with the Arabic language as impeding functional communication. Inadequate language skills and cultural disparities were identified as key factors that could adversely impact quality patient care and safety. ${ }^{[21]}$

Research examining clinical nursing and midwifery in the Gulf Cooperation Council (GCC) and East African region is extremely limited, ${ }^{[22]}$ with a paucity of qualitative studies focused on the patient experience and culturally relevant care. The findings from this initial study conducted in the western region of Abu Dhabi suggest there is need for a more in-depth exploration of healthcare needs of Emirati nations in this region. The present findings will be useful to inform such studies.

\section{Limitations}

The presence of one male only amongst those recruited to the study is a limitation, and thus this study primarily presents the perspective of female Emirati Nationals. Although this one male voice appeared to reflect similar views to those of the nine women, the researchers cannot claim this one perspective as representative of the perspective of male Emirati nationals living in the AGHS catchment area. Eight of the nine voices of adult female Emirati nationals from the region who use these health services identified themselves as frequent users of the services. Four of these women and the one male regularly accessed care for chronic diseases such as type 2 diabetes, hypertension, and hyperlipidaemia; conditions prevalent among the UAE population. ${ }^{[23,24]}$ The perspectives represented by this cohort support the design and implementation of patient-centered healthcare interventions sensitive to the cultural and spiritual needs of the female members of this cultural group, while the one male voice would suggest a need for further exploration of the male perspective. ${ }^{[25]}$

\section{Conclusions}

This exploratory study investigated previously un-researched perceptions and expectations of Emirati Nationals regarding nursing services and nurses and therefore contributes to filling an identified gap in the literature. As the findings predominantly reflect the female perspective, it is suggested that replication of this study to access the perspectives of more than one male Emirati National would be useful. These findings can also inform the design of a larger scale survey of Emirati health and nursing service users across the AGHS district and neighboring health services. In addition, the findings may inform nursing staff development efforts. Importantly, the findings counter regional perceptions of nursing being under-valued as a "servant" role across the UAE and broader GCC, and have potential to inform future initiatives regarding enhancing the image of nursing and increasing understanding of the value of nurses and their role in health services in Muslim populations across the Arab speaking world. Further investigation regarding perceptions and valuing of nursing in the Emirati community is therefore warranted.

\section{CONFLICTS OF INTEREST Disclosure}

The authors declare they have no conflicts of interest.

\section{REFERENCES}

[1] Mosadeghrad AM. Factors Influencing Healthcare Service Quality. International Journal of Health Policy and Management. 2014; 3(2): 77-89. PMid: 25114946. https://doi .org/10.15171/ijhpm.2 014.65

Published by Sciedu Press
[2] Abu Dhabi Urban Planning Council. Al Gharbia 2030. 2015. Available from: http://www.upc.gov.ae/abu-dhabi-2030/al-g harbia-2030. aspx?lang=en-US

[3] Statistics Centre of Abu Dhabi. Statistical yearbook of Abu Dhabi 2015. 2015. Available from: https://www.scad.ae/en/Pages 
/ThemeReleaseDetail. aspx?ReleaseID=652\&ThemeID=1

[4] Aqtash S, Robb WF, Hunter LH, et al. Self-Assessed Competence of Experienced Expatriate Nurses in a Rural and Remote Setting. Sage Open. 2017; 3(3): 1-17. https : //doi .org/10.1177/23779608 17702382

[5] Squires A. Language barriers and qualitative nursing research: methodological considerations. International Nursing Review. 2008; 55(3): 265-273. PMid: 19522941. https://doi.org/10.1111/j . 1466-7657.2008.00652.x

[6] Yin RK. Qualitative Research from Start to Finish. Guilford Publications. 2010.

[7] Yin RK. Analyzing Qualitative Data, I: Compiling, Disassembling, and Reassembling in Qualitative Research from Start to Finish. Guilford Publications. 2010; 176-204. PMid: 20684968.

[8] Jasmine T. Art, Science, or Both? Keeping the Care in Nursing. Nursing Clinics. 2009; 44(4): 415-421. https ://doi.org/10.1 016/j.cnur.2009.07.003

[9] Alligood MR. Nursing theorists and their work. St Louis, United States: Elsevier Health Sciences; 2013. PMid: 23464815.

[10] Abdellah FG, Beland IL, Martin A, et al. Patient-centered approaches to nursing. New York: Macmillan; 1960.

[11] Watson J. Nursing: the philosophy and science of caring. 1st ed. Colorado, United States: University Press of Colorado; 1979.

[12] Watson J. Nursing: the philosophy and science of caring. Revised ed. Colorado, United States: University Press of Colorado; 2008.

[13] Wilkes L, Cowin L, Johnson M, et al. A montage of the qualities of the registered nurse. International Nursing Review. 2014; 61(4): 555562. PMid: 25269608. https://doi.org/10.1111/inr. 12134

[14] Slater P, McCance T, McCormack B. The development and testing of the Person-centred Practice Inventory - Staff (PCPI-S). International Journal for Quality in Health Care. 2017; 29(4): 541-547. PMid: 28586441. https://doi.org/10.1093/intqhc/mzx066

[15] Lovering S. Arab Muslim nurses experiences of the meaning of caring, in Faculty of Health Sciences. University of Sydney. 2008
[16] Lovering S. Caring as an Act of Spirituality: a Nursing Approach, in Cultural Competence in Caring for Muslim Patients, G.H. Rassool, Editor. Palgrave Macmillan: Hampshire; 2014. 27-38 p.

[17] Melhem GA, Zeilani RS, Zaqqout OA, et al. Nurses' Perceptions of Spirituality and Spiritual Care Giving: A Comparison Study Among All Health Care Sectors in Jordan. Indian Journal of Palliative Care. 2016; 22(1): 42. PMid: 26962280. https ://doi.org/10.4103/ 0973-1075. 173949

[18] Sadat Hoseini AS, Alhani F, Khosropanah AH, et al. A concept analysis of nursing based on islamic sources: seeking remedy. International Journal of Nursing Knowledge. 2013; 24(3): 142-149. https : //doi .org/10.1111/j.2047-3095.2013.01244.x

[19] Rudolfsson G, Berggren I, da Silva AB. Experiences of spirituality and spiritual values in the context of nursing - an integrative review. Open Nursing Journal. 2014; 8: 64-70. PMid: 25598856. https://doi .org/10.2174/1874434601408010064

[20] El-Haddad M. Nursing in the United Arab Emirates: an historical background. International Nursing Review. 2006; 53(4): 2849. PMid: 17083417. https ://doi.org/10.1111/j.1466-7657. $2006.00497 . \mathrm{x}$

[21] Alahmmari AY. Exploring cultural barriers to effective communication between expatriate nurses and patients in the Kingdom of Saudi Arabia. Monash University. 2016.

[22] Alhusaini M, Sun C, Larson E. Clinical nursing and midwifery research in Middle Eastern and North African Countries: A Scoping Review. Journal of Health Specialties. 2016; 4(4): 238-245. https://doi.org/10.4103/2468-6360.191904

[23] Hajat C, Harrison O, Shather Z. A profile and approach to chronic disease in Abu Dhabi. Globalization and Health. 2012; 8(1): 1-12. PMid: 22738714. https://doi.org/10.1186/1744-8603-8-18

[24] Hajat C, Harrison O, Al Siksek Z. Weqaya: A Population-Wide Cardiovascular Screening Program in Abu Dhabi, United Arab Emirates. American Journal of Public Health. 2012; 102(5): 909-914. PMid: 21940918. https://doi.org/10.2105/AJPH. 2011.300290

[25] Dearholt SL, Dang D. Johns Hopkins Nursing Evidence-Based Practice: Models and Guidelines. Indianapolis, United States: Sigma Theta Tau International; 2008. PMid: 22970528. 